\title{
Doses e épocas de aplicação de nitrogênio no feijoeiro irrigado cultivado em plantio direto
}

\author{
Flávia de Andrade Meira( ${ }^{(1)}$, Marco Eustáquio de Sá(1), Salatiér Buzetti(1) e Orivaldo Arf(1)
}

(1)Universidade Estadual Paulista “Júlio de Mesquita Filho", Fac. de Engenharia, Caixa Postal 31, CEP $15385-000$ IIha Solteira, SP.
E-mail: mesa@agr.feis.unesp.br, sbuzetti@agr.feis.unesp.br, arf@agr.feis.unesp.br

Resumo - O nitrogênio é o nutriente exigido em maiores quantidades pela cultura do feijão. A resposta à sua aplicação depende da dose aplicada e da época de sua aplicação. O objetivo deste trabalho foi avaliar os componentes de produção, produtividade de grãos e a qualidade fisiológica de sementes de feijão, decorrentes de diferentes doses de $\mathrm{N}$ (uréia) aplicadas em cobertura em três estádios da cultura. $\mathrm{O}$ experimento foi conduzido no sistema plantio direto. Os tratamentos foram constituídos por 0, 40, 80, 120,160, 200 e $240 \mathrm{~kg} \mathrm{ha}^{-1} \mathrm{de} \mathrm{N}$ aplicados em cobertura nos estádios $\mathrm{V}_{4-5}, \mathrm{R}_{5}$ e $\mathrm{R}_{6}$, correspondendo, respectivamente, a 21, 32 e 38 dias após a emergência das plantas. A qualidade fisiológica de sementes foi avaliada por meio do teste de germinação e testes de vigor. $\mathrm{O} N$ aplicado nas diferentes fases da cultura não interferiu nos componentes de produção. A máxima produtividade de grãos foi obtida com $164 \mathrm{~kg} \mathrm{ha}^{-1} \mathrm{de} \mathrm{N}$ em cobertura, independentemente do estádio de desenvolvimento. A qualidade fisiológica das sementes não foi influenciada pelos tratamentos.

Termos para indexação: Phaseolus vulgaris, estádios de desenvolvimento, resíduos vegetais, qualidade de sementes, componentes de produção.

\section{Doses and time of nitrogen top-dressed application for common bean in no-till system}

\begin{abstract}
The nitrogen is the nutrient required in greatest quantities by the bean crop and the response to its application depends on the applied $\mathrm{N}$ rate as well as the time of its application. The objective of this work was to evaluate yield components, grain productivity and physiological quality of bean seeds, affected by different nitrogen (urea) rates top-dressed at three crop growth stages. The experiment was conducted in no-till system. The treatments were constituted by $0,40,80,120,160,200$ and $240 \mathrm{~kg} \mathrm{ha}^{-1} \mathrm{~N}$ top-dressed at $\mathrm{V}_{4-5}, \mathrm{R}_{5}$ and $\mathrm{R}_{6}$ growth stages, corresponding to 21, 32 and 38 days after plant emergence, respectively. Seed physiological quality was evaluated by germination and vigor tests. Nitrogen applied at different crop growth stages did not interfere on the yield components, but interfered on bean productivity. Maximum grain productivity was obtained with topdressed $164 \mathrm{~kg} \mathrm{ha}^{-1} \mathrm{~N}$, independently of growth stage application. Seed physiological quality was not affected by the treatments, fitting in the category of seeds for commercialization.
\end{abstract}

Index terms: Phaseolus vulgaris, crop growth stages, vegetable residues, seed quality, components of productivity.

\section{Introdução}

O feijoeiro (Phaseolus vulgaris L.) é exigente em nutrientes, em decorrência, principalmente, do seu sistema radicular reduzido e pouco profundo, além de seu ciclo curto, de 90 a 100 dias (Rosolem \& Marubayashi, 1994). Por isso, os nutrientes devem ser aplicados de forma que fiquem próximos do sistema radicular da planta, para serem absorvidos no momento em que a planta os necessitar.

Por ser o nutriente mais absorvido e o mais exportado pelas plantas, o N deve ser reposto (Silva et al., 2000).
Entre as deficiências nutricionais que ocorrem na cultura do feijão, a de $\mathrm{N}$ é a mais freqüente, devendo-se precisar a dose e época corretas, de modo a propiciar boa nutrição da planta no momento em que ainda é possível aumentar o número de vagens por planta, ou seja, até o início do florescimento (Carvalho et al., 2001). Segundo Neptune \& Muraoka (1978), quando aplicado antes ou durante o florescimento, a utilização do $\mathrm{N}$ foi maior do que quando aplicado na semeadura.

De acordo com Rosolem (1987), o aproveitamento desse nutriente é maior quando aplicado em cobertura no máximo até 36 dias após a emergência das plantas. 
Já Araújo et al. (1994) verificaram que a adubação nitrogenada parcelada, em cobertura, até os 30 dias após a emergência das plantas (DAE) é vantajosa para a cultura do feijão. Calvache \& Reichardt (1996) verificaram que a maior absorção de $\mathrm{N}$ ocorreu na floração e na época de formação de vagens. Ambrosano et al. (1996), avaliando a aplicação de N em cobertura no cultivo de feijão irrigado no inverno, constataram que a produtividade pode ser aumentada pela adição de $\mathrm{N}$, e que as doses únicas aplicadas em cobertura foram mais eficientes do que as aplicadas somente na semeadura, com melhor época de aplicação aos 25 DAE.

Nos trópicos, a decomposição da palhada em sistema de plantio direto é rápida (Sanchez \& Logan, 1992), exigindo que plantas que tenham uma relação $\mathrm{C} / \mathrm{N}$ mais ampla sejam utilizadas no sistema, permitindo assim uma retenção de palha por mais tempo. Essa situação favorece bastante o uso do arroz no sistema, uma vez que esta planta tem uma relação $\mathrm{C} / \mathrm{N}$ alta, essencial para a manutenção da palhada na superfície do solo por maior período, além das melhorias nas propriedades físicas do solo.

Stone \& Moreira (2001) verificaram que o número de vagens por planta, massa de cem sementes e produtividade do feijoeiro responderam significativamente a $0,20,40$ e $60 \mathrm{~kg} \mathrm{ha}^{-1} \mathrm{de} \mathrm{N}$, aplicados aos $35 \mathrm{DAE}$, sob o sistema de plantio direto. Constataram ainda que houve aumento na produtividade com o decorrer de vários anos de cultivo com o incremento das doses desse nutriente. Soratto et al. (2001) constataram que a aplicação de 0, 25, 50, 75 e $100 \mathrm{~kg} \mathrm{ha}^{-1}$ de $\mathrm{N}$ em cobertura, aos 15, 25 e 35 DAE proporcionou melhor desenvolvimento e aumentos da produtividade da cultura do feijão irrigado, cultivado em sistema de plantio direto.

O objetivo deste trabalho foi avaliar os componentes de produção, produtividade de grãos e a qualidade fisiológica de sementes de feijão, em função de diferentes doses de N (uréia) aplicadas em cobertura em três estádios da cultura.

\section{Material e Métodos}

O trabalho foi realizado na área experimental da Fazenda de Ensino e Pesquisa da Fac. de Engenharia da Unesp, Campus de Ilha Solteira, localizada no Município de Selvíria, MS. O solo foi classificado como um Latossolo Vermelho distrófico típico argiloso, A moderado, hipodistrófico, álico, caulinítico, férrico, compactado, muito profundo, moderadamente ácido (Embrapa, 1999) e suas características químicas $(0-20 \mathrm{~cm})$, determinadas antes da instalação do experimento (Raij \& Quaggio, 1983), apresentaram os seguintes valores: $17 \mathrm{mg} \mathrm{dm}^{-3}$ de $\mathrm{P}_{\text {resina }} ; 1,1,31,9$ e $20 \mathrm{mmol}_{\mathrm{C}} \mathrm{dm}^{-3}$, respectivamente, de $\mathrm{K}, \mathrm{Ca}, \mathrm{Mg}$ e $\mathrm{H}+\mathrm{Al}$; $\mathrm{pH}\left(\mathrm{Ca} \mathrm{Cl}_{2}\right), 5,7 ; 22 \mathrm{~g} \mathrm{~kg}^{-1}$ de matéria orgânica e $67 \%$ de saturação por bases (V\%). A cultura anterior foi o arroz, e realizou-se a dessecação do material vegetal da área com aplicação do herbicida glyphosate (1.440 g ha-1 do i.a.) para posterior semeadura da cultivar IAC Carioca em 10/5/2002.

A adubação básica nos sulcos de semeadura foi realizada levando-se em consideração a análise do solo e as recomendações de Ambrosano et al. (1997), utilizando-se $40 \mathrm{~kg} \mathrm{ha}^{-1}$ de $\mathrm{P}_{2} \mathrm{O}_{5}$ (superfosfato simples) e $20 \mathrm{~kg} \mathrm{ha}^{-1} \mathrm{~K}_{2} \mathrm{O}$ (cloreto de potássio). As sementes foram distribuídas em sulcos com o objetivo de se obter 12 plantas por metro de linha de sulco e o espaçamento de $0,5 \mathrm{~m}$ entrelinhas. $\mathrm{O}$ controle de plantas daninhas foi realizado aos $27 \mathrm{DAE}$, quando as mesmas evidenciavam pleno desenvolvimento vegetativo (estádio $V_{3} / V_{4}$ ), mediante o uso de herbicida fluazifop-p-butil (125 g ha-1 $^{-1}$ do i.a.).

A aplicação do $\mathrm{N}$ em cobertura foi realizada nos dias 7/6/2002 - estádio $V_{4-5}$ (quinta folha trifoliolada em mais de $50 \%$ das plantas), correspondendo aos $21 \mathrm{DAE}-$, 18/6/2002 - estádio $\mathrm{V}_{4-9}$ (primeiros botões florais em mais de $50 \%$ das plantas), estando as plantas com aproximadamente 11 a 12 folhas trifolioladas, correspondendo aos $32 \mathrm{DAE}$ - e 25/6/2002 - estádio $\mathrm{R}_{6}$ (primeira flor aberta em $50 \%$ das plantas), correspondendo aos 38 DAE. A fonte de $\mathrm{N}$ foi uréia e, após a aplicação, foi efetuada irrigação com a finalidade de minimizar as perdas de $\mathrm{N}$ por volatilização. As irrigações foram realizadas pelo sistema de irrigação por aspersão convencional. Os tratos culturais e fitossanitários foram os recomendados para a cultura na região. Foi realizada aplicação da mistura monocrotophos (175 $\mathrm{g} \mathrm{ha}^{-1}$ do i.a.) + mancozeb (1.600 g ha-1 do i.a.) aos 20 DAE, uma aplicação da mistura methamidophos (600 g ha-1 do i.a.) + benomil (250 g ha-1 do i.a.) aos 38 DAE, e uma aplicação da mistura monocrotophos (175 g ha-1 do i.a.) + benomil (250 $\mathrm{g} \mathrm{ha}^{-1}$ do i.a.) aos 55 DAE.

O florescimento das plantas iniciou-se aos 31 DAE. A colheita foi realizada manualmente, em 16/8/2002, totalizando um ciclo de 91 dias. Na determinação do número de plantas, foram obtidos entre 11-12 plantas $\mathrm{m}^{-1}$, correspondendo a um estande final de aproximadamente 230.000 plantas ha $^{-1}$. 
O delineamento experimental utilizado foi de blocos casualizados com 21 tratamentos e quatro repetições, constituídos de 0, 40, 80, 120, 160, 200 e $240 \mathrm{~kg} \mathrm{ha}^{-1}$ de $\mathrm{N}$ aplicados em cobertura em três estádios de desenvolvimento da cultura $\left(\mathrm{V}_{4-5}, \mathrm{R}_{5}\right.$ e $\mathrm{R}_{6}$, correspondendo a 21, 32 e 38 DAE, respectivamente). As parcelas foram constituídas de seis linhas de $4 \mathrm{~m}$ de comprimento, sendo considerada como área útil as quatro linhas centrais, desprezando-se 0,5 m em ambas as extremidades de cada linha.

Foram registradas as datas de florescimento pleno, estádio $\mathrm{R}_{6}$, dias compreendidos entre a emergência até a presença da primeira flor aberta em $50 \%$ das plantas; de final do ciclo, dias decorridos desde a emergência das plantas de feijão até a colheita; e da colheita. Na época da colheita, coletaram-se dez plantas de cada parcela, determinando-se altura de plantas, altura de inserção da primeira vagem, número de vagens planta $^{-1}$, número de sementes vagem ${ }^{-1}$, massa de 100 sementes e, em duas linhas centrais de cada parcela (área útil), foi determinado o número de plantas e produtividade de grãos.

O teste de germinação foi realizado com quatro subamostras de 50 sementes para cada tratamento, em rolos de papel-toalha Germitest à temperatura constante de $25^{\circ} \mathrm{C}$. As contagens foram realizadas aos quatro e sete dias após a semeadura, de acordo com Brasil (1992). Em seguida, foi realizada a primeira contagem de germinação - obtida em conjunto com o teste de germinação, computando-se as porcentagens de plântulas normais verificadas no quarto dia após a semeadura, em técnica semelhante à adotada por Burris et al. (1969) - e determinado o envelhecimento acelerado em quatro subamostras de 50 sementes para cada tratamento, segundo McDonald \& Phaneendranath (1978), descrito por Marcos Filho (1994). Em cada caixa de plástico (Gerbox) foram adicionados $40 \mathrm{~mL}$ de água destilada, e posteriormente foram colocadas 200 sementes sobre a tela de inox do gerbox. A seguir o recipiente foi tampado e as caixas foram levadas ao germinador regulado à temperatura de $42^{\circ} \mathrm{C}$, onde permaneceram por 60 horas.

As sementes foram semeadas conforme descrito para o teste de germinação, com a avaliação das plântulas normais sendo realizada aos cinco dias após a instalação do teste, para avaliação do vigor das sementes.

O Sistema de Análise Estatística - SANEST (Zonta \& Machado, 1991) foi utilizado na análise de variância. Com relação às doses de $\mathrm{N}$, aplicaram-se análises de regressão.

\section{Resultados e Discussão}

Não houve efeito significativo das épocas de aplicação de $\mathrm{N}$, assim como das doses e sua interação, às avaliações realizadas, exceto para a produtividade de grãos, em que houve efeito das doses de nitrogênio (Tabela 1).

Quanto à altura de plantas, a média de 80,8 cm está dentro da característica da cultura, assim como a altura de inserção da primeira vagem $(10 \mathrm{~cm})$ e número de vagens por planta $(10,82 \mathrm{~cm})$ (Tabela 1$)$. Soratto et al. (2001) também constataram que a aplicação de N em cobertura em épocas distintas (15, 25 e 35 DAE) não proporcionou efeito significativo na altura de plantas, provavelmente porque o tempo não foi suficiente para proporcionar efeito no número de flores. Por sua vez, Portes (1996) constatou que plantas de feijão bem nu-

Tabela 1. Valores médios de altura de plantas, altura de inserção da 1a vagem, número de vagens por planta, número de sementes por vagem, massa de 100 sementes e produtividade de grãos, obtidos em feijoeiro cv. IAC Carioca, de acordo com doses de $\mathrm{N}$, aplicado em diferentes estádios, em plantio direto sobre palhada de arroz.

\begin{tabular}{|c|c|c|c|c|c|c|}
\hline $\begin{array}{c}\mathrm{N} \\
\left(\mathrm{kg} \mathrm{ha}^{-1}\right)\end{array}$ & $\begin{array}{l}\text { Altura de } \\
\text { plantas } \\
(\mathrm{cm})\end{array}$ & $\begin{array}{c}\text { Altura de } \\
\text { inserção da } \\
1^{\underline{a}} \text { vagem }(\mathrm{cm})\end{array}$ & $\begin{array}{l}\text { Número de } \\
\text { vagens por } \\
\text { planta }\end{array}$ & $\begin{array}{c}\text { Número de } \\
\text { sementes por } \\
\text { vagem }\end{array}$ & $\begin{array}{c}\text { Massa de } 100 \\
\text { sementes } \\
(\mathrm{g})\end{array}$ & $\begin{array}{l}\text { Produtividade } \\
\quad\left(\mathrm{kg} \mathrm{ha}^{-1}\right)\end{array}$ \\
\hline 0 & 82,83 & 9,63 & 9,15 & 5,60 & 26,96 & 3.024 \\
\hline 40 & 79,60 & 10,54 & 9,64 & 5,70 & 26,36 & 3.372 \\
\hline 80 & 81,50 & 9,69 & 11,07 & 5,50 & 26,96 & 3.510 \\
\hline 120 & 86,63 & 9,78 & 11,13 & 5,25 & 27,23 & 3.470 \\
\hline 160 & 81,28 & 11,04 & 11,32 & 5,37 & 27,57 & 3.639 \\
\hline 200 & 77,80 & 10,79 & 12,11 & 5,30 & 27,37 & 3.539 \\
\hline 240 & 75,52 & 10,34 & 11,37 & 5,29 & 27,10 & 3.516 \\
\hline $\mathrm{CV}(\%)$ & 11,37 & 19,87 & 24,89 & 8,19 & 3,58 & 10,24 \\
\hline
\end{tabular}


tridas produzem mais flores e, conseqüentemente, mais vagens por planta. O número de sementes por vagem $(5,43)$ não foi afetado significativamente, provavelmente por ser uma característica varietal pouco influenciada pelo ambiente (Andrade et al., 1998). No entanto, Arf et al. (2004) observaram que o número de sementes por vagem foi influenciado pelas doses de $\mathrm{N}$ aplicadas em cobertura, indicando que uma melhor nutrição em $\mathrm{N}$ pode aumentar o número de óvulos fertilizados por vagem, com os dados se ajustando a uma equação linear crescente. Com relação à massa de 100 sementes, com média de 27,07 g, não houve efeito significativo tanto das doses como das épocas de aplicação de $\mathrm{N}$ o que mostra que essa característica apresenta menor variação porcentual decorrente das alterações no meio de cultivo (Crusciol et al., 2001).

As doses de $\mathrm{N}$ influenciaram a produtividade de grãos, ficando evidente a participação do número de vagens por planta, já que houve correlação significativa entre estas duas avaliações $\left(r=0,86^{*}\right)$. A regressão polinomial ajustada entre a produtividade e as doses de $\mathrm{N}$ foi a quadrática $\left(\mathrm{Y}=3074,0912+6,4276 \mathrm{X}-0,0196 \mathrm{X}^{2}\right)$, com ponto de máxima obtido com $164 \mathrm{~kg} \mathrm{ha}^{-1}$ (Tabela 1). Tal dose se justifica devido à presença de material vegetal sobre o solo, deixado pela cultura anterior e com início do sistema de plantio direto.

A resposta da cultura à aplicação de $\mathrm{N}$ é controversa. Assim, Rapassi et al. (2003), testando 20, 40, 60, 80 e $100 \mathrm{~kg} \mathrm{ha}^{-1}$ de $\mathrm{N}$ com duas fontes, uréia e nitrato de amônio, no sistema plantio direto, constataram que não houve diferenças entre os níveis de produtividade em função das doses de N aplicadas. Arf et al. (1991), utilizando doses e épocas de aplicação de $\mathrm{N}$ em relação à testemunha, sob o sistema de plantio direto, verificaram que, em relação ao número de vagens por planta, sementes por vagem, sementes por planta e produtividade de grãos, não houve efeito significativo. Os autores justificaram tal resultado pelo alto teor de matéria orgânica do solo que, mediante sua mineralização, liberaria quantidades suficientes de $\mathrm{N}$ para atender às necessidades da planta. Carvalho et al. (2003) verificaram que, quanto à produtividade de grãos, não houve efeito significativo de aplicação de $\mathrm{N}$, mas quanto às doses de $\mathrm{N}(0,35$, 70, 105 e $140 \mathrm{~kg} \mathrm{ha}^{-1}$ de N), a produtividade máxima seria alcançada com a dose superior a $140 \mathrm{~kg} \mathrm{ha}^{-1} \mathrm{de}$ nitrogênio. Também Sá et al. (1992) observaram que a produtividade aumentou linearmente, com o incremento da dose de $\mathrm{N}\left(0,20,40,60\right.$ e $\left.80 \mathrm{~kg} \mathrm{ha}^{-1}\right)$ aos $20 \mathrm{DAE}$; metade aos 20 DAE e metade aos 40 DAE, e a forma mais adequada de aplicação foi o parcelamento. Silveira \& Damasceno (1993) constataram efeito significativo de $0,30,60$ e $90 \mathrm{~kg} \mathrm{ha}^{-1}$ de $\mathrm{N}$, aplicados $1 / 3$ no plantio e 2/3 em cobertura aos $30 \mathrm{DAE}$, sobre a produtividade de grãos, e a máxima produtividade foi alcançada com a dose de $72 \mathrm{~kg} \mathrm{ha}^{-1}$ de N. Buzetti et al. (1992) constataram aumento linear na produtividade de cerca de 4,33 $\mathrm{kg} \mathrm{ha}^{-1}$ de grãos para cada kg de $\mathrm{N}$ aplicado $(0,20$, 40, 60 e $80 \mathrm{~kg} \mathrm{ha}^{-1}$ ). O parcelamento da aplicação (metade aos 20 DAE e o restante aos $40 \mathrm{DAE}$ ) aumentou a massa de 100 grãos e a produtividade de grãos. Rosolem (1996) ressaltou que as condições de resposta ao $\mathrm{N}$ estão relacionadas com o solo do local de semeadura (cultura anterior, teor de matéria orgânica, textura do solo e irrigação). Segundo Chidi et al. (2002), cultivares e variações de clima também podem influenciar a resposta da cultura à aplicação do nitrogênio.

Não houve efeito significativo entre os tratamentos quanto à germinação, vigor e primeira contagem, provavelmente em decorrência da época de semeadura do feijoeiro (período seco), da não ocorrência de doenças e da nutrição adequada das plantas (Tabela 2). Estes

Tabela 2. Valores médios de germinação, vigor e primeira contagem de sementes, obtidos em feijoeiro cv. IAC Carioca, de acordo com doses de N, aplicado em diferentes estádios, em plantio direto sobre palhada de arroz.

\begin{tabular}{|c|c|c|c|c|c|c|c|c|c|}
\hline \multirow{2}{*}{$\begin{array}{c}\mathrm{N} \\
\left(\mathrm{kg} \mathrm{ha}^{-1}\right)\end{array}$} & \multicolumn{9}{|c|}{ Época de aplicação de N (dias após a emergência) } \\
\hline & 21 & 32 & 38 & 21 & 32 & 38 & 21 & 32 & 38 \\
\hline & \multicolumn{3}{|c|}{--------Germinação (\%)-------- } & \multicolumn{3}{|c|}{---------Vigor (\%)--------- } & \multicolumn{3}{|c|}{----Primeira contagem $(\%)-----$} \\
\hline 0 & 83 & 98 & 99 & 99 & 100 & 97 & 83 & 98 & 98 \\
\hline 40 & 88 & 73 & 98 & 100 & 100 & 100 & 82 & 66 & 96 \\
\hline 80 & 98 & 99 & 84 & 99 & 99 & 97 & 96 & 95 & 75 \\
\hline 120 & 95 & 92 & 94 & 98 & 100 & 95 & 89 & 84 & 89 \\
\hline 160 & 99 & 93 & 99 & 99 & 97 & 96 & 99 & 89 & 100 \\
\hline 200 & 90 & 93 & 98 & 98 & 100 & 97 & 88 & 88 & 96 \\
\hline 240 & 98 & 90 & 99 & 99 & 98 & 100 & 97 & 83 & 92 \\
\hline
\end{tabular}


resultados são pouco relevantes, já que os valores de germinação e vigor as enquadram como sementes aptas para a comercialização (Brasil, 1992), cujo padrão de germinação deve ser de $80 \%$, com tolerância de 5\%.

\section{Conclusões}

1. O nitrogênio aplicado nos diferentes estádios de desenvolvimento da cultura não interfere nos componentes de produção e na qualidade fisiológica das sementes do feijoeiro.

2. O nitrogênio aplicado aumenta a produtividade de grãos e esta se correlaciona com o número de vagens por planta.

3. A dose de nitrogênio recomendada em cobertura é de $164 \mathrm{~kg} \mathrm{ha}^{-1}$, independentemente da época aplicação.

\section{Referências}

AMBROSANO, E.J.; TANAKA, R.T.; MASCARENHAS, H.A.A.; RAIJ, B. van; QUAGGIO, J.A.; CANTARELLA, H. Leguminosas e oleaginosas. In: RAIJ, B. van; CANTARELLA, H.; QUAGGIO, J.A.; FURLANI, A.M.C. (Ed.). Recomendações de adubação e calagem para o Estado de São Paulo. 2.ed. Campinas: Instituto Agronômico/Fundação IAC, 1997. p.187-203. (Boletim Técnico, 100).

AMBROSANO, E.J.; WUTKE, E.B.; AMBROSANO, G.M.B.; BULISANI, E.A.; BORTOLETTO, N.; MARTINS, A.L.M.; PEREIRA, J.C.V.N.A.; DE SORDI, G. Efeito do nitrogênio no cultivo de feijão irrigado no inverno. Scientia Agricola, v.53, p.338-341, 1996.

ANDRADE, M.J.B.; DINIZ, A.R.; CARVALHO, J.G.; LIMA, S.F. Resposta da cultura do feijoeiro à aplicação foliar de molibdênio e às adubações nitrogenadas de plantio e cobertura. Ciência e Agrotecnologia, v.22, p.499-508, 1998.

ARAÚJO, G.A.A.; VIEIRA, C.; MIRANDA, G.V. Efeito da época de aplicação do adubo nitrogenado em cobertura sobre o rendimento do feijão, no período de outono-inverno. Revista Ceres, v.41, p.442-450, 1994.

ARF, O.; FORNASIERI FILHO, D.; MALHEIROS, E.B.; SATTO, S.M.T. Efeito da inoculação e adubação nitrogenada em feijoeiro (Phaseolus vulgaris L.), cultivar Carioca 80: 1. Solo de alta fertilidade. Científica, v.19, p.29-38, 1991.

ARF, O.; RODRIGUES, R.A.F.; SÁ, M.E.; BUZETTI, S.; NASCIMENTO, V. Manejo do solo, água e nitrogênio no cultivo de feijão. Pesquisa Agropecuária Brasileira, v.39, p.131-138, 2004.

BRASIL. Ministério da Agricultura e Reforma Agrária. Secretaria de Defesa Agropecuária. Departamento Nacional de Defesa Vegetal. Regras para análise de sementes. Brasília, 1992. 365p.

BURRIS, J.S.; EDJE, O.T., WAHAB, A.H. Evaluation of various indices of seed and seedling vigour in soybean (Glycine max (L.)
Merril). Proceedings of the Association of Official Seed Analysts, v.59, p.73-81. 1969.

BUZETTI, S.; ROMEIRO, P.J.M.; ARF, O.; SÁ, M.E.; GUERREIRO NETO, G. Efeito da adubação nitrogenada em componentes da produção do feijoeiro (Phaseolus vulgaris L.) cultivado em diferentes densidades. Cultura Agronômica, v.1, p.11-19, 1992.

CALVACHE, A.M.; REICHARDT, K. Efeito de épocas de deficiência hídrica na eficiência do uso do nitrogênio da cultura do feijão cv. Imbabello. Scientia Agricola, v.53, p.342-353, 1996.

CARVALHO, M.A.C.; ARF, O.; SÁ, M.E.; BUZETTI, S.; SANTOS, N.C.B.; BASSAN, D.A. Produtividade e qualidade de sementes de feijoeiro (Phaseolus vulgaris L.) sob influência de parcelamentos e fontes de nitrogênio. Revista Brasileira de Ciência do Solo, v.25, p.617-624, 2001.

CARVALHO, M.A.C.; FURLANI JUNIOR, E.; ARF, O.; SÁ, M.E.; PAULINO, H.B.; BUZETTI, S. Doses e épocas de aplicação de nitrogênio e teores foliares deste nutriente e de clorofila em feijoeiro. Revista Brasileira de Ciência do Solo, v.27, p.445-450, 2003.

CHIDI, S.N.; SORATTO, R.P.; SILVA, T.R.B.; ARF, O.; SÁ, M.E.; BUZETTI, S. Nitrogênio via foliar e em cobertura em feijoeiro irrigado. Acta Scientiarum, v.24, p.1391-1395, 2002.

CRUSCIOL, C.A.C.; LIMA, E.V.; ANDREOTTI, M.; LEMOS, L.B.; NAKAGAWA, J.; FURLANI JUNIOR, E. Adubação nitrogenada de semeadura e de cobertura sobre a produtividade do feijoeiro. Cultura Agronômica, v.10, p.119-133, 2001.

EMBRAPA. Centro Nacional de Pesquisa de Solos (Rio de Janeiro, RJ). Sistema brasileiro de classificação de solos. Rio de Janeiro: Embrapa-CNPS; Brasília: SPI, 1999. 412p.

MARCOS FILHO, J. Teste de envelhecimento acelerado. In: VIEIRA, R.D.; CARVALHO, N.M. Teste de vigor em sementes. Jaboticabal: Funep, 1994. p.133-149.

NEPTUNE, A.M.L.; MURAOKA, T. Aplicação de uréia- ${ }^{15} \mathrm{~N}$ em feijoeiro (Phaseolus vulgaris L.) cultivar Carioca. Revista Brasileira de Ciência do Solo, v.2, p.51-55, 1978.

PORTES, T.A. Ecofisiologia. In: ARAÚJO, R.S.; RAVA, C.A.; STONE, L.F.; ZIMMERMANN, M.J. de O. (Coord.). Cultura do feijoeiro comum no Brasil. Piracicaba: Potafos, 1996. p.101-131.

RAIJ, B. van; QUAGGIO, J.A. Métodos de análise de solo para fins de fertilidade. Campinas: Instituto Agronômico, 1983, 31p. (Boletim Técnico, 81).

RAPASSI, R.M.A.; SÁ, M.E.; TARSITANO, M.A.A.; CARVALHO, M.A.C. de; PROENÇA, E.R.; NEVES, C.M.T. de C.; COLOMBO, E.C.M. Análise econômica comparativa após um ano de cultivo do feijoeiro irrigado, no inverno, em sistemas de plantio convencional e direto, com diferentes fontes e doses de nitrogênio. Bragantia, v.62, p.397-404, 2003.

ROSOLEM, C.A. Calagem e adubação mineral. In: ARAÚJO, R.S.; RAVA, C.A.; STONE, L.F.; ZIMMERMANN, M.J. de O. (Coord.). Cultura do feijoeiro comum no Brasil. Piracicaba: Potafos, 1996. p.353-390.

ROSOLEM, C.A. Nutrição e adubação do feijoeiro. Piracicaba: Potafos, 1987. 93p. (Boletim Técnico, 8) 
ROSOLEM, C.A.; MARUBAYASHI, O.M. Seja o doutor do seu feijoeiro. Informações agronômicas, v.68, p.1-16, 1994. (Encarte especial).

SÁ, M.E.; BUZETTI, S.; ARF, O.; TAKAHATA, M.H.; STRADIOTO, M.F.; NUNES, M.E.T. Efeitos de doses e do parcelamento de nitrogênio na produção e qualidade de sementes do feijoeiro. Cultura Agronômica, v.1, p.31-45, 1992.

SANCHEZ, P.A.; LOGAN, T.J. Myths and science about the chemistry and fertility of soils in the tropics. In: LAL, R.; SANCHEZ, P.A. (Ed.). Myths and science of soil of the tropics. Madison: Soil Science Society of America, 1992. p.35-46. (Special publication, 29).

SILVA, T.R.B.; SORATTO, R.P.; CHIDI, S.N.; ARF, O.; SÁ, M.E.; BUZETTI, S. Doses e épocas de aplicação de nitrogênio em cobertura na cultura do feijoeiro de inverno. Cultura agronômica, v.9, p.1-17, 2000.

SILVEIRA, P.M.; DAMASCENO, M.A. Doses e parcelamento de $\mathrm{K}$ e de $\mathrm{N}$ na cultura do feijoeiro irrigado. Pesquisa Agropecuária Brasileira, v.28, p.1269-1276, 1993.

SORATTO, R.P.; SILVA, T.R.B.; ARF, O.; CARVALHO, M.A.C. Níveis e épocas de aplicação de nitrogênio em cobertura no feijoeiro irrigado em plantio direto. Cultura Agronômica, v.10, p.89-99, 2001.

STONE, L.F.; MOREIRA, J.A.A. Resposta do feijoeiro ao nitrogênio em cobertura,sob diferentes lâminas de irrigação e preparos do solo. Pesquisa Agropecuária Brasileira, v.36, p.473-481, 2001.

ZONTA, E.P.; MACHADO, A.A. SANEST: sistema de análise estatística para microcomputadores. Piracicaba: Ciagri/Esalq-USP, 1991.120p

Recebido em 4 de agosto de 2004 e aprovado em 5 de novembro de 2004 